Original paper

\title{
Aspergillus sakultaensis, a new species in section Flavipedes isolated from Sohag Governorate, Egypt
}

\author{
Abdel-Naser A. Zohri ${ }^{1}$, Osama A. Al-Bedak ${ }^{2}$ and Marwa M. Abdel-Kareem ${ }^{3 *}$ \\ ${ }^{1}$ Department of Botany \& Microbiology, Faculty of Science, Assiut University, Assiut, 71511, Egypt \\ ${ }^{2}$ Assiut University Mycological Centre, Assiut University, Assiut, 71511, Egypt \\ ${ }^{3}$ Department of Botany \& Microbiology, Faculty of Science, Sohag University, Sohag, 82511, Egypt \\ doi:
}

\begin{abstract}
During the routine sampling from Atawayel canal at Atawayel village, Sakulta city, Sohag Governorate, Egypt and isolation of fungi from these water samples, an interesting isolate of Aspergillus was recovered. The phenotypic characteristics of the isolate revealed its strong relationship to Aspergillus section Flavipedes. Sequencing of the Internal Transcribed Spacer (ITS) gene demonstrated that the isolate is a new species belonging to section Flavipedes. The new taxon morphological characters exhibited a huge differentiation between other species in brightly yellow mycelium color on MEA and CYA at $25{ }^{\circ} \mathrm{C}$ and on MEA, CYA, Cz and CREA at $30{ }^{\circ} \mathrm{C}$, conidiophore length (up to $3 \mathrm{~mm}$ ), accessory conidia absence and hull cells shape. The new strain was described and illustrated as A. sakultaensis. A pure culture of the new taxon was deposited in the culture collection of the Assiut University Mycological Centre as AUMC 13885, uploaded in MycoBank as MB 831480 and the ITS sequence was uploaded to GenBank as MK391495.
\end{abstract}

\section{KEYWORDS}

Aspergillus,

Flavipedes,

New taxon,

Phylogeny,

ITS.

CORRESPONDING AUTHOR

Marwa M. Abdel-Kareem

marwaabdelkareem7@gmail.com

\section{INTRODUCTION}

The genus Aspergillus is one of the best-known and most studied fungi that occupying various habitats worldwide since the description of the genus Aspergillus from almost 300 years ago by Micheli (Dyer \& O'Gorman 2012). They found in terrestrial habitats and are commonly isolated from soil particularly in tropical and subtropical environments (Carroll \& Wicklow 1992; Klich 2002; Domsch et al. 2007). They also isolated from foods, indoor environments and as endophytes as well as from several cases of human and animal infections including osteomyelitis, cutaneous aspergillosis, otomycosis, onychomycosis and diskospondylitis (Stuart \& Blank 1955; Roselle \& Baird 1979; Barson \&
Ruymann 1986; Schultz et al. 2008; Gehlot et al. 2011).

Aspergillus species have been described morphologically into 18 groups (Raper \& Fennell 1965) namely: clavatus, gluacus, ornatus, cervineus, restrictus, fumigatus, ochraceus, niger, candidus, flavus, wentii, cremeus, sparsus, versicolor, nidulans, ustus, flavipes, and terreus. Depending on biochemical and molecular analysis, Aspergillus species were distinguished into eight groups namely: Eurotium, Fumigati, Ornati, Clavati, Nidulantes, Circumdati, Stilbothamnium and Ochraceoroseus (Samson 1992; Verga et al. 2000; Klich 2006). Traditionally, filamentous fungi have been defined by morphology, wherein a species is recognized as 
a group of isolates that share a set of morphological characteristics distinguishing it from other isolates. Thus, identification of aspergilli is based upon a cumulative evaluation of their colony characteristics and microscopic morphology: color of the aerial parts of the Aspergillus colony, pigmentation of the basal mycelium or the underlying exudates, the rate of colony growth, the texture of the surface growth of the colony, growth zones and colony topography (Balajee et al. 2006). However, the morphological identification of Aspergillus suffers from several limitations and recognizing these limitations as early as 1965, Raper and Fennell noted that in studying aspergilli, it is important to realize that strains may vary within a species, that species may vary within a group and that groups overlap within the genus (Raper \& Fennell 1965). Several recent studies have brought into focus the difficulties of phenotypic methods of identification in aspergilla (Alsohaili \& BaniHasan 2018).

Molecular identification of the filamentous fungi was conducted based on sequence of mitochondrial cytochrome $\mathrm{b}$ gene (Wang et al. 2001), mycotoxin regulatory genes, alkaloids (Chang et al. 1995), DNA topisomerase gene (Kanbe et al. 2002), and ribosomal RNA identity (Hinrikson et al. 2005). However, ribosomal RNA regions as 18S rRNA and internal transcribed spacers (ITS 1 and ITS 2), between the small and large subunit, is a universal fungal probe as species-species identifiers for saprophytic filamentous fungi (White et al. 1990; Henry et al. 2000; Iwen et al. 2002; De-Aguirre et al. 2004). Furthermore, the 5'-end of the large rRNA subunit (D1 and D2 domain) have been studied to emphasize the molecular approaches for identification of fungi (Scorzettiet et al. 2002; Hall et al. 2004; Peterson 2008). Schoch et al. (2012) proposed the use of nuclear ITS sequences for BarCode identification of fungal species. Others have included additional loci such at $\beta$ tubulin or calmodulin to confidently identify isolates (Peterson 2012). While DNA sequence analysis is perhaps the most accurate method of species identification, it is still to provide descriptions that allow for recognition of the species with morphological criteria. The Aspergillus flavipes group (Thom \& Church 1926) originally contained only A. flavipes while Raper \& Fennell (1965) placed A. flavipes, A. carneus and A. niveus in the group. Gams et al. (1985) erected Aspergillus section Flavipedes to contain species of the informal A. flavipes group.

The addition of new species of fungi isolated from different environments will remain one of the most important goals of scientific research to identify the treasures contained in those environments that may have a great impact in the areas of discovering and producing new useful materials. In this study, a new interesting species of fungi belonging to Aspergillus section Flavipedes was isolated during the routine sampling from Atawayel canal at Atawayel village, Sakulta city, Sohag Governorate, Egypt and identified based on their phenotypic and genetic characters.

\section{MATERIALS \& METHODS}

\section{Sampling site}

Sohag Governorate is located in the southern part of Egypt (Upper Egypt), and covers a stretch of the Nile Valley. It lies between $26.56^{\circ} \mathrm{N}$ and $31.7^{\circ} \mathrm{E}$ with total area of $11022 \mathrm{~km}^{2}$ and extends $125 \mathrm{~km}$ long and 16-25 km wide. The governorate consists of 12 centers, comprising 12 cities, 3 districts and 51 major villages. The inhabited area is about $1593.92 \mathrm{~km}^{2}$, about $14.5 \%$ of the total area of the Governorate. Using sterile 1L bottles, water samples were collected from Atawayel canal at Atawayel village, Sakulta city, Sohag Governorate.

\section{Strain isolation}

The fungus was isolated from a water sample using pour plate technique (Sanders 2012) on potato dextrose agar of the following composition $(\mathrm{g} / \mathrm{L})$ : potato infusion from $200 \mathrm{~g}$, glucose, 20 and agar, 20. Rose Bengal (0.05 g/L) and chloramphenicol $(0.25 \mathrm{~g} / \mathrm{L})$ were added to the medium to prevent the bacterial growth. The medium $\mathrm{pH}$ was adjusted at 7.3. After autoclaving, 
aliquots of $20 \mathrm{ml}$ medium were poured into sterile Petri plates each containing $1 \mathrm{ml}$ of water sample. The Cultures were then incubated for 7-15 days at $25^{\circ} \mathrm{C}$. The developing fungal colonies were isolated as pure cultures and maintained in slants of MEA at $4^{\circ} \mathrm{C}$. One of the fungal isolates expected to be a new species was sent to the Assiut University Mycological Centre for reidentification and preservation in the culture collection.

\section{Phenotypic studies}

Morphological characteristics of the fungal isolate were studied by culturing on different media such as Yeast Extract Sucrose agar (YES, Frisvad 1981), Malt Extract Agar (MEA, Samson et al. 2010), Czapek Yeast Autolysate agar (CYA, Pitt 1979), Czapek's agar (Cz, Raper \& Thom 1949) and Creatine sucrose agar (CREA, Frisvad 1981). Plates were inoculated in three-point pattern using a micropipette and inoculum size of $1 \mu 1$ per spot. Unwrapped plates were incubated in the dark reverse side up at $25{ }^{\circ} \mathrm{C}$. Microscopic features of the fungal culture grown on MEA were examined in lacto-phenol cotton blue mounts.

\section{Molecular characterization of the fungal isolate}

\section{DNA extraction}

The protocol employed in Moubasher et al. (2019) was followed, in which $0.2 \mathrm{~g}$ of 7-day-old fungal mycelia of A. sakultaensis grown on MEA, were grounded using liquid nitrogen and transferred to $1.5 \mathrm{ml}$ microfuge tubes. $800 \mu \mathrm{l}$ CTAB buffer composed of $3 \%$ CTAB, $1.4 \mathrm{M}$ $\mathrm{NaCl}, 0.2 \%$ Mercaptoethanol, 20 mM EDTA, 100 $\mathrm{mM}$ TRIS-HCl pH 8.0 and $1 \%$ PVP-40, were added to each tube. After incubation at $65{ }^{\circ} \mathrm{C}$ for $30 \mathrm{~min}, 800 \mu \mathrm{l}$ of CI Mix with the composition of $24 \mathrm{ml}$ chloroform and $1 \mathrm{ml}$ isoamyl alcohol, were gently added and mixed with the tube contents. A clear supernatant was obtained by centrifugation at $10000 \mathrm{xg}$ for $10 \mathrm{~min}$. For DNA precipitation $2 / 3$ volume of isopropanol (precooled at $-20{ }^{\circ} \mathrm{C}$ ) was added and mixed gently. The samples were incubated at $4{ }^{\circ} \mathrm{C}$ overnight, thereafter centrifugation at $13000 \mathrm{xg}$ for $10 \mathrm{~min}$. The supernatant was discarded, and the pellet was pooled and washed with $200 \mu \mathrm{l}$ washing buffer composed of $76 \%$ ethanol and $10 \mathrm{mM}$ ammonium acetate. The washing buffer was carefully decanted, and the pellet was suspended in $200 \mu \mathrm{l}$ TE buffer supplemented with $10 \mathrm{mg} / \mathrm{ml}$ RNase. After incubation at $37^{\circ} \mathrm{C}$ for $30 \mathrm{~min}, 100 \mu 1$ of 7.5 $\mathrm{M}$ ammonium acetate and $750 \mu \mathrm{l}$ ethanol were added and mixed gently. Samples were centrifuged at $13000 \mathrm{xg}$ for $10 \mathrm{~min}$ at room temperature. The supernatant was completely discarded, and the pellet was suspended in $100 \mu \mathrm{l}$ sterile distilled water.

\section{PCR amplification and sequencing of rDNA using ITS1 and ITS4 primers}

The fungal DNA was sent to SolGent Company, South Korea for polymerase chain reaction (PCR) and sequencing of rRNA gene. PCR was performed using SolGent EF-Taq and the universal primers ITS1 and ITS4 (White et al. 1990). In the PCR tubes $1 \mu$ of DNA template, 1 $\mu 12.5 \mathrm{mM}$ dNTP mix, 0.2 unit of Taq polymerase, $5 \mu \mathrm{l}$ of $10 \mathrm{x}$ complete buffer and $40 \mu \mathrm{l}$ of sterile $\mathrm{ddH}_{2} \mathrm{O}, 10$ pmol of ITS1 (5' TCC GTA GGT GAA CCT TGC GG 3') and ITS4 (5' TCC TCC GCT TAT TGA TAT GC 3') were added. Then the PCR amplification was carried out using the following sequence: one round of amplification consisting of denaturation at $95{ }^{\circ} \mathrm{C}$ for $15 \mathrm{~min}$ followed by 30 cycles of denaturation at $95{ }^{\circ} \mathrm{C}$ for $20 \mathrm{sec}$, annealing at $50{ }^{\circ} \mathrm{C}$ for $40 \mathrm{sec}$ and extension at $72{ }^{\circ} \mathrm{C}$ for $1 \mathrm{~min}$, with a final extension step of $72{ }^{\circ} \mathrm{C}$ for $5 \mathrm{~min}$. The PCR products were then purified with the SolGent PCR Purification Kit-Ultra (SolGent, Daejeon, South Korea) prior to sequencing. The purified PCR products were confirmed on $1 \%$ agarose gel by electrophoresis using 100 bpDNA ladder as a size marker. The bands were eluted and sequenced in the forward and reverse directions using the same pimers and incorporation of ddNTPs in the reaction mixture. The obtained sequences were analyzed using Basic Local Alignment Search Tool (BLAST) from the National Center of Biotechnology Information (NCBI) website. 


\section{Phylogenetic analyses}

The phylogenetic analysis was inferred by the Maximum Likelihood method based on the General Time Reversible model (Nei \& Kumar 2000). The bootstrap consensus tree inferred from 100 replicates (Felsenstein 1985) is taken to represent the evolutionary history of the taxa analyzed (Felsenstein 1985). Branches corresponding to partitions reproduced in less than $50 \%$ bootstrap replicates are collapsed. The percentage of replicate trees in which the associated taxa clustered together in the bootstrap test (100 replicates) are shown next to the branches (Felsenstein 1985). Initial tree(s) for the heuristic search were obtained automatically by applying the Maximum Parsimony method. A discrete Gamma distribution was used to model evolutionary rate differences among sites (5 categories $(+\mathrm{G}$, parameter $=0.1000)$. The rate variation model allowed for some sites to be evolutionarily invariable ([+I], $48.95 \%$ sites). The analysis involved 15 nucleotide sequences. All positions with less than $95 \%$ site coverage were eliminated. That is, fewer than $5 \%$ alignment gaps, missing data, and ambiguous bases were allowed at any position. There were 522 positions in the final dataset. Evolutionary analyses were conducted in MEGA7 (Kumar et al. 2016).

\section{RESULTS}

\section{Phylogenetic analysis}

The phylogenetic analysis was inferred using the Maximum Likelihood method based on the General Time Reversible model. The tree with the highest log likelihood (-794.17) is shown in Figure 1. The ITS data set composed of 15 sequences including the ITS sequence of $A$. sakultaensis. The new species was consistently grouped with $A$. flavipes, A. templicola, and A. mangaliensis forming a highly supported clade.

Sources, localities and percentages coverage and similarity of Aspergillus strains aligned with $A$. sakultaensis.

Data in table 1 summarise some basic information on 16 Aspergillus strains closely related to the strain isolated in the current study.
Although A. sakultaensis showed $100 \%$ similarity with some strains of $A$. flavipes and $A$. mangalensis (from Turkey, China, Egypt and Czech Republic), the percentages of sequence coverage were generally low $(91 \%-95 \%)$. This means that $A$. sakultaensis is still geneitically different from these strains. Another important criterion is the low percentages of identity and coverage of A. sakultaensis sequences $(98.04 \%$ and $94 \%$ respectively) when aligned with those of the type material of A. flavipes NRRL302T (NR_135397). Similar observations of low identity and coverage can be observed with sequences of the type strains of A. neoflavipes, $A$. templicola, A. frequens and A. lizukae as shown in Table 1.

\section{Taxonomy}

Aspergillus sakultaensis OA Al-Bedak, AA Zohri \& MM Abel-Kareem sp. nov. Fig. (2) GenBank: ITS=MK391495

MycoBank: MB 831480

Typification: EGYPT. Sohag Governorate: Sakulta city, Atawayel village, from water sample of Atawayel canal, 10Aug 2018, Marwa AbdelKareem, MAK-2008 (Holotype AUMC13885).

Etymology: Named after Sakulta city in Sohag Governorate (Egypt) that is located close to the place of isolation.

\section{Cultural characteristics}

Colonies on MEA reaching a diameter of 26-30 $\mathrm{mm}$ in 7 days at $25^{\circ} \mathrm{C}$, velutinous to floccose with granular surface, plane, zonate, with moderately raised central part of colonies, brownish-grey to greyish brown (5C2-5D3) in the center, margin entire, paler with yellow to vivid yellow mycelia (2A7-2A8) forming complete zone around the colony center, reverse raw umber to brownishgrey (5F8-6F8), On CYA after 7 days at $25{ }^{\circ} \mathrm{C}$, colonies attaining a diameter of $28-30 \mathrm{~mm}$, brownish orange to greyish brown (5C3-5D3) in the center, velutinous to floccose with granular surface, zonate, radially wrinkled with raised colony center, yellow mycelia (2A7-3A7) form a complete zone around the center, $2-3 \mathrm{~mm}$ from the 
margin, margin paler, entire, reverse light brown to yellowish brown (5D6-8 - 5E6-8). On Cz after 7 days at $25{ }^{\circ} \mathrm{C}$ colonies attaining $16-18 \mathrm{~mm}$ diameter, brownish grey to greyish brown $(5 \mathrm{C} 2$ 5D3) in the center, floccose with granular surface, zonate, plane, margin entire, paler than the center, reverse greyish orange (5B4-5) to brownish orange (5C4). On CREA colonies reaching 20-23 mm diameter after 7 days at $25{ }^{\circ} \mathrm{C}$, velutinous to floccose, plane, slightly sulcate, brownish grey to greyish brown $(5 \mathrm{C} 2-5 \mathrm{D} 3)$ in the center, margin entire, white, reverse reddish brown (8D-F7), no acid production. Colonies in 7 days at $30{ }^{\circ} \mathrm{C}$ attaining a diameter of 32-35 mm on MEA, 29-30 $\mathrm{mm}$ on CYA and $\mathrm{Cz}$, and 27-30 $\mathrm{mm}$ on CREA, yellow mycelia dominant on all media.

Colonies on CYA at $37{ }^{\circ} \mathrm{C}$ after 7 days were similar to those on CYA at $30{ }^{\circ} \mathrm{C}$ attaining a diameter of 28-30 mm. and dominant yellow mycelia (Figure 2).

Conidial heads brownish-grey to greyish brown (5C2-5D3), loosely columnar to radiate, conidiophores biseriate, stipes hyaline to light brown, smooth-walled, up to $3 \mathrm{~mm}$ long $\times 5-8 \mu \mathrm{m}$ width $(\mathrm{n}=50)$, diminutive conidiophores not observed. Vesicles variable in shape, globose, subglobose or spathulate, most commonly, (10 -) 12-20 $\mu \mathrm{m}$ diameter $(\mathrm{n}=50)$, metulae $4-6 \mu \mathrm{m}$ long $(\mathrm{n}=50)$, phialides $6.0-7.5 \mu \mathrm{m}$ long $(\mathrm{n}=50)$, Conidia globose, subglobose, polygonal, mostly $2-3 \mu \mathrm{m}$ in diameter $(n=50)$. Accessory conidia not observed. Hülle cells formed as yellow mycelial clumps, variable in shape and dimensions, globose, elliptical, ossiform, lobate, irregularly elongated and narrow, exudate colourless. No ascomata or ascospores observed (Figure 3).

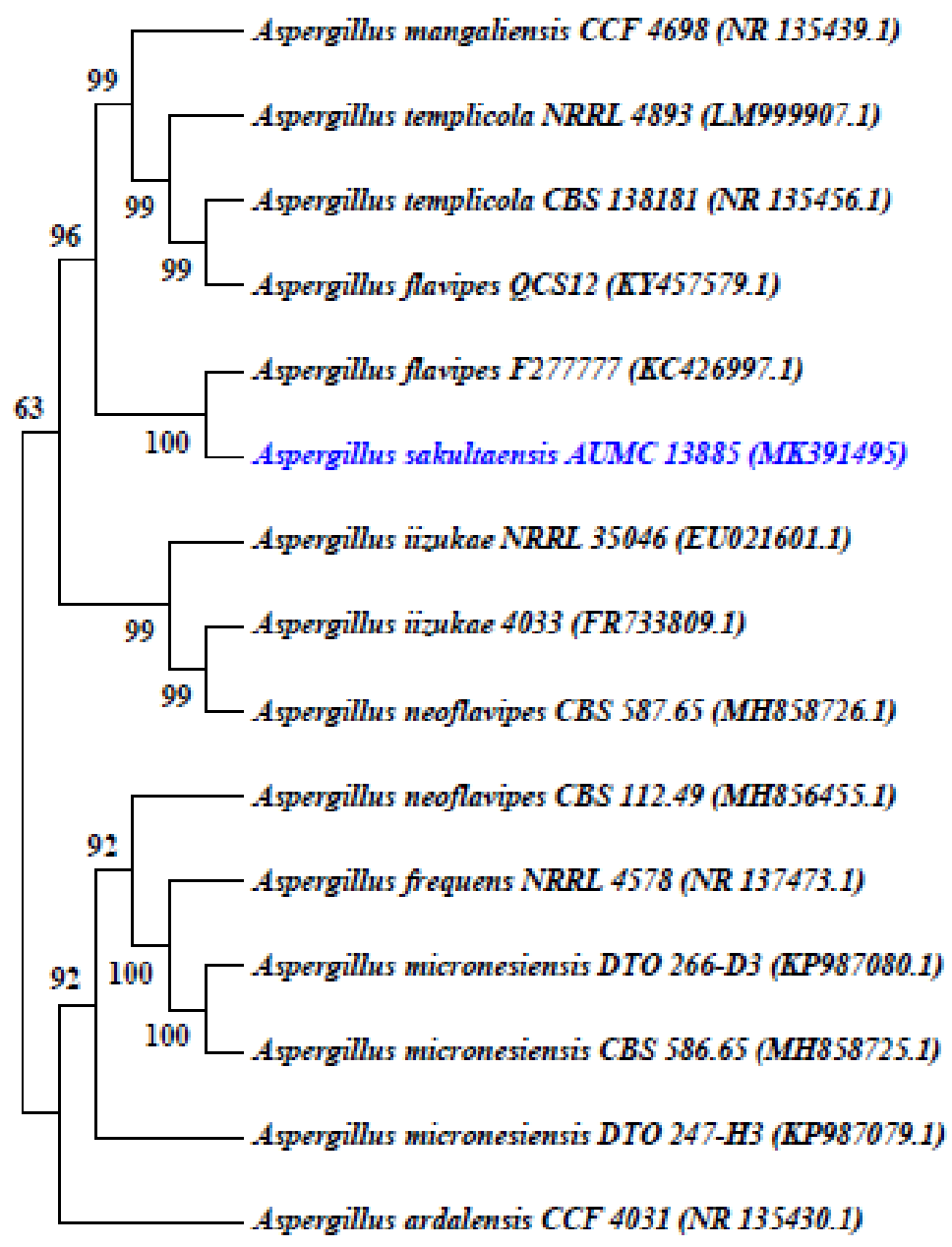

Figure (1) Maximum Likelihood phylogenetic tree of Aspergillus sakultaensis AUMC13885 with other related Aspergillus species in section Flavipedes based on their nucleotide sequences of the ITS region. The new species in blue color. 
Table (1) Sources, localities and percentages coverage and similarity of Aspergillus strains aligned with A. sakultaensis

\begin{tabular}{|c|c|c|c|c|c|c|c|}
\hline \multirow{2}{*}{$\begin{array}{l}\text { Aspergillus } \\
\text { strain of the } \\
\text { current } \\
\text { study }\end{array}$} & \multicolumn{7}{|c|}{ Closely related strains of Aspergillus accessed from the GenBank ( $T=T y p e$ material) } \\
\hline & Fungal species & Strain No. & $\begin{array}{l}\text { Accession } \\
\text { No. }\end{array}$ & Source & Country & Coverage & Similarity \\
\hline \multirow{16}{*}{$\begin{array}{c}\text { Aspergillus } \\
\text { sakultaensis } \\
\text { AUMC } \\
13885 \\
\text { (MK391495) } \\
\text { from a water } \\
\text { sample, } \\
\text { Sohag/Egypt }\end{array}$} & A. flavipes & QCS12 & KY457579 & Soil & China & $98 \%$ & $99.66 \%$ \\
\hline & A. flavipes & 63 & KF671231 & $\begin{array}{l}\text { Leaves of } \\
\text { Stevia } \\
\text { rebaudiana }\end{array}$ & India & $98 \%$ & $99.14 \%$ \\
\hline & A. flavipes & F277777 & KC426997 & Soil & Spain & $96 \%$ & $99.82 \%$ \\
\hline & A. flavipes & 08CK020 & KF938457 & $\begin{array}{l}\text { marine } \\
\text { sediment }\end{array}$ & Turkey & $94 \%$ & $! 00 \%$ \\
\hline & A. flavipes & M1 & HM595494 & $\begin{array}{l}\text { endophytes of } \\
\text { Abies } \\
\text { beshanzuensi } \\
\text { s }\end{array}$ & China & $95 \%$ & $100 \%$ \\
\hline & A. flavipes & AUMC1201 & MN428799 & Soil & Egypt & $95 \%$ & $100 \%$ \\
\hline & A. flavipes & DTO303-14 & KP987083 & Unknown & Iran & $99 \%$ & $97.97 \%$ \\
\hline & A. flavipes & NRRL 302T & NR 135397 & Unknown & USA & $94 \%$ & $98.04 \%$ \\
\hline & A. flavipes & E14 & GU566238 & $\begin{array}{l}\text { Rhizosphere } \\
\text { of Phalaris } \\
\text { arundinacea }\end{array}$ & $\begin{array}{c}\text { Czech } \\
\text { Republic }\end{array}$ & $99 \%$ & $97.98 \%$ \\
\hline & A. neoflavipes & NRRL5504T & NR_137475 & Unknown & USA & $94 \%$ & $98.21 \%$ \\
\hline & A. mangaliensis & CCF4698 & NR_135439 & $\begin{array}{l}\text { European } \\
\text { caves }\end{array}$ & $\begin{array}{c}\text { Czech } \\
\text { Republic }\end{array}$ & $91 \%$ & $100 \%$ \\
\hline & A. templicola & CBS138181T & NR_135456 & $\begin{array}{l}\text { indoor house } \\
\text { dust }\end{array}$ & Moxico & $91 \%$ & $99.81 \%$ \\
\hline & A. templicola & DTO 267-H4 & KP987081 & Unknown & Iran & $99 \%$. & $99.48 \%$ \\
\hline & A. frequens & NRRL4578T & NR_137473 & Unknown & USA & $94 \%$ & $98.04 \%$ \\
\hline & A. ardalensis & CCF4031T & NR_135430 & Soil & $\begin{array}{c}\text { Czech } \\
\text { Republic }\end{array}$ & $94 \%$ & $98.40 \%$ \\
\hline & A. lizukae & NRRL3750T & NR_135398 & Unknown & USA & $94 \%$ & $98.05 \%$ \\
\hline
\end{tabular}

\section{Distinguishing features}

Long conidiophore (up to $3 \mathrm{~mm}$ ), brightly yellow mycelia on MEA and CYA at $25^{\circ} \mathrm{C}$ and on MEA, CYA, $\mathrm{Cz}$ and CREA at $30^{\circ} \mathrm{C}$, as well as absence of accessory conidia are the distinguishable morphological characters that differentiate the new taxon from other species in section Flavipedes.

\section{DISCUSSION}

The novel species in the present study was isolated from a freshwater sample collected from Atawayel canal, Sakulta city, Sohag Governorate, Egypt. The morphological examination of the new taxon in the current study showed typical phenotypic characteristics of Aspergillus section Flavipedes. The sequencing of the ITS gene revealed the strong relationship of the new taxon with members of section Flavipedes. Phylogenetic tree showed that the new species A. sakultaensis was consistently grouped in subclade with $A$. flavipes, A. templicola and A. mangaliensis.

In section Flavipedes, the cultural morphology is very useful in the differentiation between species, since brightly yellow mycelia are present in A. sakultaensis colonies on MEA and CYA at $25^{\circ} \mathrm{C}$ and on MEA, CYA, Cz and CREA at $30^{\circ} \mathrm{C}$, in $A$. ardalensis on MEA, and in both $A$. neoflavipes and A. luppii on all media at $25{ }^{\circ} \mathrm{C}$, while colonies of A. movilensis are whitish and those of the remaining species are mostly in shades of brown at $25{ }^{\circ} \mathrm{C}$. In addition, the red or brownish soluble pigment is present in A. iizukae and $A$. frequens while it is absent in $A$. sakultaensis. 

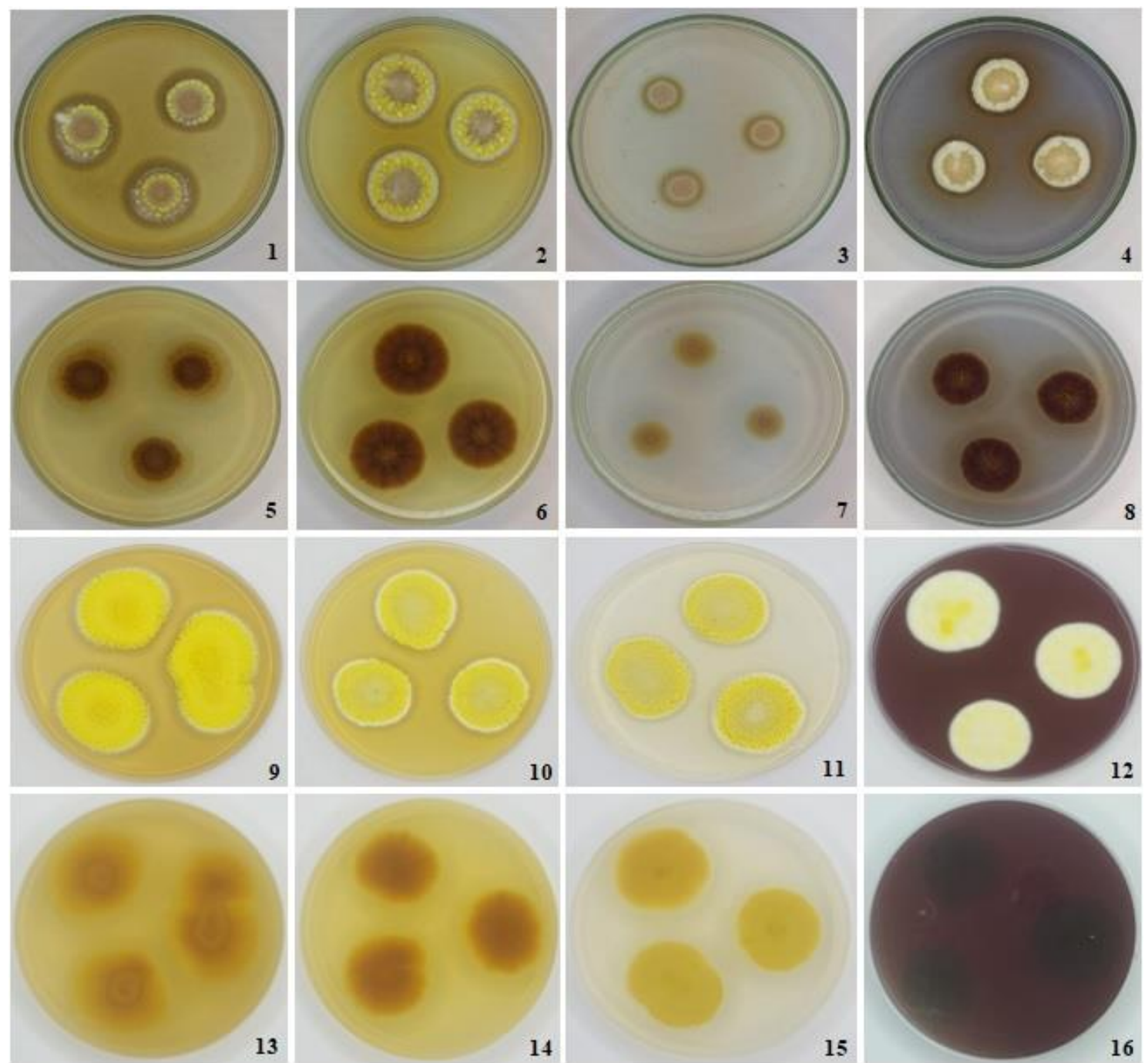

Figure (2) Aspergillus sakultaensis AUMC13885. Colonies after 7 days at $25^{\circ} \mathrm{C}, \mathbf{1 - 4}$ : on MEA, CYA, CZ and CREA at $25^{\circ} \mathrm{C}$; 5-8: reverse on MEA, CYA, CZ and CREA at $25^{\circ} \mathrm{C}$; 9-12: on MEA, CYA, Cz and CREA at $30{ }^{\circ} \mathrm{C}$; 13-16: reverse on MEA, CYA, $\mathrm{Cz}$ and CREA at $30^{\circ} \mathrm{C}$.

The vesicle shape and diameter are also very important features in species differentiation as the vesicles of $A$. flavipes are predominantly spathulate and their diameter not exceeding $11 \mu \mathrm{m}$ and mostly with a constriction at the base, those of A. iizukae commonly exceed $20 \mu \mathrm{m}$ diam in contrast to other species while A. sakultaensis has globose, subglobose or spathulate vesicles, that most commonly measure $12-20 \mu \mathrm{m}$ diameter and this character can distinguish the new species from A. flavipes and A. iizukae.

Conidiophore is another important morphological character that helps in species differentiation in this section. The conidiophore of A. sakultaensis is a distinctive morphological character among other members of the section. It measures up to $3 \mathrm{~mm}$ long being the longest conidiophore recorded in all species in section Flavipedes, while the conidiophores of $A$. ardalensis, A. mangaliensis, A. flavipes, A. frequens, A. iizukae, A. movilensis, A. neoflavipes, A. templicola, A. micronesiensis and A. capensis may exceed $1 \mathrm{~mm}$ long but they are shorter than that of A. sakultaensis. In addition to the previous morphological features, Hülle cells are considered as important microscopic criteria that help in the differentiation between these species. In $A$. sakultaensis, Hülle cells are formed as masses of yellow clumps at the colony margin, Hülle cells are variable in shape and dimensions, globose, elliptical, ossiform, lobate, irregularly elongated and narrow. They resemble those of A. frequens, A. iizukae, A. mangaliensis and A. movilensis while A. flavipes, A. frequens and A. polyporicola 
lack Hülle cells in their cultures. Also, the accessory conidia are missing in the new taxon; which considered, with the long conidiophore, the most distinguishable morphological characters that can differentiate A. sakultaensis from all other species in section Flavipedes.

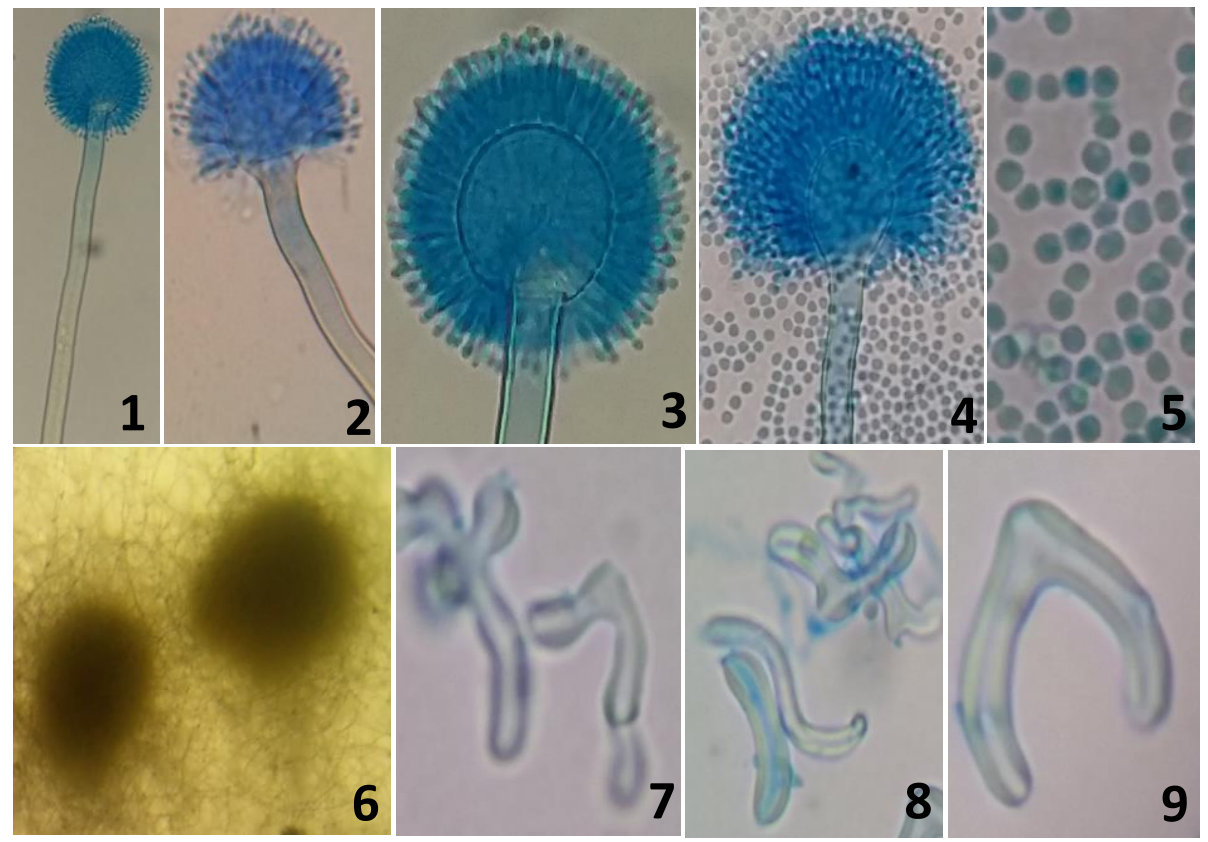

Figure (3) Aspergillus sakultaensis AUMC13885. 1-4: Conidial heads; 5: conidia; 6: clumps of Hülle cells; 7-9: Hülle cells with different shapes.

\section{CONCLUSION}

In this research, a new interesting species of fungi named Aspergillus sakultaensis belonging to Aspergillus section Flavipedes was isolated, described, identified and added to the science. The studies are still ongoing on this fungal species in our laboratory by the same researcher group to identify its physiological characteristics and the possibility of using it in producing compounds of economic value.

\section{REFERENCES}

Alsohaili, S.A., Bani-Hasan, B.M. (2018). Morphological and Molecular Identification of Fungi Isolated from Different Environmental Sources in the Northern Eastern Desert of Jordan. Jordan J Biol. Sci. 11: $329-337$.

Balajee, S.A., Marr K.A. (2006). Phenotypic and genotypic identification of human pathogenic aspergilli. Future Microbiol. 1(4):435-445.
Balajee, S.A., Nickle, D., Varga, J., Marr, K.A. (2006). Molecular studies reveal frequent misidentification of Aspergillus fumigatus by morphotyping. Eukaryot. Cell 5(10): 1705-1712.

Barson, W., Ruymann, F. (1986). Palmar aspergillosis in immunocompromised children. J Pediatr Infect Dis 5: 264-268.

Carroll, G.C., Wicklow, D.T. (1992). The fungal community, its organization and role in the ecosystem, 2nd edn. Marcel Dekker, New York.

Chang, P.K., Bhatnagar, D., Cleveland, E., Bennett, J.W. (1995). Sequence variability in homolgs of the aflatoxin pathway gene aflR distinguishes species in Aspergillus section Flavi. Appl. Environ. Microbiol. 61:40-43.

De-Aguirre, L., Hurst, S.F., Choi, J.S., Shin, J.H., Hinrikson, H.P., Morrison, C.J. (2004). Rapid differentiation of Aspergillus species 
from other medically important opportunistic molds and Yeasts by PCREnzyme Immunoassay. J. Clin. Microbiol. 42:3495-3504.

Domsch, K.H., Gams, W., Anderson, T.H. (2007). Compendium of soil fungi, 2nd Ed. Eching: IHW-Verlag.672 p.

Dyer, P.S., O’Gorman, C.M. (2012). Sexual development and cryptic sexuality in fungi: insights from Aspergillus species. FEMS Microbiol Rev 36:165-192.

Fries, E.M. (1832). Systema Mycologicum. E. Mauritius, Gryphiswald. Frisvad JC. 1981. Physiological criteria and mycotoxin production as aids in identification of common asymmetric Penicillia. Appl. Environ. Microbiol. 41: 568-579.

Gams, W., Christensen, M., Onions, A.H., Pitt, J.I., Samson, R.A. (1985). Infrageneric taxa of Aspergillus. In: Samson RA, Pitt JI, eds. Advances in Penicillium and Aspergillus Systematics. New York: Plenum Press. p $55-62$.

Gehlot, P., Purohit, D., Singh, S. (2011). Molecular diagnostics of human pathogenic Aspergillus species. Indian $\mathrm{J}$ Biotechnol 10:207-211.

Hall, L., Wohlfiel, S., Roberts, G.D. (2004). Experience with the MicroSeq D2 large subunit ribosomal DNA sequencing kit for identification of commonly encountered, clinically important yeast species. J. Clin. Microbiol. 41:5099-5102.

Henry, T., Iwen, P.C., Hinrichs, S.H. (2000). Identification of Aspergillus species using internal transcribed spacer regions 1 and 2 . J. Clin. Microbiol. 38:1510-1515.

Hinrikson, H.P., Hurst, S.F., Lott, T.J., Warnock, D.W., Morrison, C.J. (2005). Assessment of ribosomal large-subunit D1D2, internal transcribed spacer 1, and internal transcribed spacer 2 regions as targets for molecular identification of medically important Aspergillus species. J. Clin. Microbiol. 43(5): 2092-2103.

Hinrikson, H.P., Hurst, S.F., Lott, T.L., Warnock, D.W., Morrison, C.J. (2005). Assessment of ribosomal large-subunit D1D2, Internal transcribed spacer 1, and internal transcribed spacer 2 regions as targets for molecular identification of medically important Aspergillus species. J. Clin. Microbiol. 43:2092-2103.

Iwen, P.C., Hinrichs, S.H., Rupp, M.E. (2002). Utilization of the internal transcribed spacer regions as molecular targets to detect and identify human fungal pathogens. Med. Mycol. 40(1): 87-109.

Jones, D.T., Taylor, W.R., Thornton, J.M. (1992). The rapid generation of mutation data matrices from protein sequences. Comput Appl Biosci 8: 275-282.

Kanbe, M., Yamaki, K., Kikuchi, A. (2002). Identification of the pathogenic Aspergillus species by nested PCR using a mixture of species primers to DNA topoisomerase II gene. Microbiol. Immunol. 46:841-848.

Klich, M.A. (2006). Identification of Clinically relevant Aspergilli. Med. Mycol. 44:S127S131.

Kumar, S., Stecher, G., Li, M., Knyaz, C., Tamura, K. (2018). MEGA X: Molecular Evolutionary Genetics Analysis across computing platforms. Mol Biol Evol 35:1547-1549.

Moubasher, A.H., Ismail, M.A., Al-Bedak, O.A., Mohamed, R.A. (2019). Ramophialophora chlamydospora, a new species from an alkaline lake of Wadi-ElNatron, Egypt. AJOM 2(1): 110-117. 
Peterson, S.W. (2008). Phylogenetic analysis of Aspergillus species using DNA sequences from four loci. Mycologia 100:205-226.

Peterson, S.W. (2012). Aspergillus and Penicillium identification using DNA sequences: barcode or MLST? Appl Microbiol Biotechnol 95:339-344,

Pitt, J.I. (1979). The genus Penicillium and its teleomorphic states Eupenicillium and Talaromyces. Academic Press Inc, London.

Raper, K.B., Fennell, D.I. (1965). The genus Aspergillus. Baltimore: Williams \& Wilkins Co. 686 p.

Raper, K.B., Thom, C. (1949). A manual of the penicillia. The Williams \& Wilkins Company, Baltimore.

Roselle, G.A., Baird, I.M. (1979). Aspergillus flavipes group osteomyelitis. Arch Intern Med 139: 590-592.

Samson, R.A. (1992). Current taxonomic schemes of the genus Aspergillus and its teleomorphs. In: Bennett JW, Klich, MA. (eds). Aspergillus Biology and Industrial Applications. Boston MA: ButterworthHeinemann. 329-353.

Samson, R.A., Houbraken, J., Thrane, U., et al. (2010). Food and indoor fungi. CBS KNAW Biodiversity Center, Utrecht.

Sanders, E.R. (2012). Aseptic laboratory techniques: plating methods. J Vis Exp 63, 3064.

Schoch, C.L., Seifert, K.A., Huhndorf, S., Spouge, R.V., Levesque, C.A., Chen,W., Fungal Barcoding Consortium (2012). Nuclear ribosomal internal transcribed spacer (ITS) region as a universal DNA barcode marker for fungi. Proc Natl Acad Sci U S A 109:6241-6246.
Schultz, R., Johnson, E., Wisner, E., Brown, N., Byrne, B., Sykes, J. (2008). Clinicopathologic and diagnostic imaging characteristics of systemic aspergillosis in 30 dogs. J Vet Intern Med 22: 851-859.

Scorzettiet, G., Fel, J.W., Fonseca, A., StatzellTallman, A. (2002). Systematics of basidiomycetous yeasts: a comparison of large subunit D1/D2 and internal transcribed spacer rDNA regions. FEMS Yeast Res. 2:496-517.

Stuart, E., Blank, F. (1955). Aspergillosis of the ear: a report of twenty-nine cases. Can Med Assoc J 72: 334-337.

Thom, C., Churchm M.B. (1926). The Aspergilli. Baltimore: Williams \& Wilkins. $272 \mathrm{p}$.

Varga, J., Toth, B., Kocsube, S. et al. (2005). Evolutionary relationships among Aspergillus terreus isolates and their relatives. Antonie Van Leeuwenhoek 88(2): 141-150.

Verga, J., Toth, B., Rigo, K., Teren, J., Kozakiewicz, Z., Hoekstra, R.F. (2000). Phylogenetic analysis of Aspergillus section Circumsdati based on sequences of the internal transcribed spacer regions and the 5.8SrRNA gene. Fungal Genet. Biol. 30:7180 .

Wang, L., Yokoyama, K., Takahasai, H., Kase, N., Hanya, Y., Yoshiro, K., Miyaji, M., Nishimura, K. (2001). Identification of species in Aspergillus section Flavi based on sequencing of the mitochondrial cytochrome b gene. Int. J. Food Microbiol. 71:75-86.

White, T.J., Bruns, T., Lee, S.J.W.T., Taylor, J.L. (1990). Amplification and direct sequencing of fungal ribosomal RNA genes for phylogenetics, PCR protocols a guide to methods and applications 18: 315-322. 